\title{
Product Recommendation Making Based on User Behavior and User location and Potential of E-commerce for SMEs in a Globalizing Business Environment
}

\author{
Sumanta Chatterjee, Nilesh Kumar, Dipu Keshri, Debarishi Saha
}

\begin{abstract}
This paper demonstrates the idea for globalization of small and medium enterprises (SMEs) using product recommendation based on user behaviour and user location. E-commerce platform is fast emerging as a new trend in global trade and SMEs should use this medium to get direct access to the world markets. As SMEs play an important role in exports, manufacturing and employment generation, there is a need to address their issues related with product selection, regulations, intellectual property rights and standards. This research paper will provide easy and smooth way to help SMEs to get the benefit of e-commerce and globalize to international market. In this paper we are going to propose a marketing strategy that will help the customer to get updates about the products which are not available at their location. This paper proposes a recommendation approach in which we will collect the user location and based on that location we will perform data mining and find the products which are not available at the customer's location.
\end{abstract}

Index Terms - recommendation system, user location detection, SMEs, marketing strategy, globalization.

\section{INTRODUCTION}

In this research paper we are going to purpose a model which will take the benefits of user's location and user behavior to create a better sale process. The main objective of this research is to understand the working of current E-commerce website and make it more powerful using our idea. Suppose a person is living at some location and suddenly he gets a recommendation of a product which is not available at his location, then he will be surely interested to at least have a look of that product.

Similarly, in this research work we are going to detect the user's location that are coming to our website and then we will collect details of that location and find out about different products which are not available at the user's location.

\section{SPECIFICATIONS}

The paper works on creating an e-commerce site model. In this model all the features of an e-commerce website are

Mr.Sumanta Chatterjee, Computer science \& Engineering, JIS College of Engineering, Kaylani, India,

Nilesh Kumar, Computer science \& Engineering, JIS College of Engineering, Kaylani, India,

Dipu Keshri, Computer science \& Engineering, JIS College of Engineering, Kaylani, India.

Debarishi Saha, Computer science \& Engineering, JIS College of Engineering, Kaylani, India. implemented with a friendly user interface. The website is divided into two sections:

\section{A. Homepage for customers}

In the homepage there is option for login and signup and after logging to website a customer can add products to his cart and buy products. When the user will sign up, the website will give him a prompt message to give his permission to share his location with us.

\section{B. Admin panel for the sellers}

The admin panel is a friendly user interface for sellers to add his product to website. The seller can view the user's coming to our website and can get an estimate of their behavior. They can see in which sector the customers are interested and what are the products are mostly searched on the website. Some of the specifications of the research work are as follows:

(i) Product and component based

(ii) Creating and changing product details at ease

(iii) User accounts to control the access and maintain security

(iv)Easy and Fast retrieval of information

(v) Cart System

(vi) Admin Panel for sellers

(vii) Friendly User Interface.

\section{RECOMMENDATION ENGINE}

At first, while we know little about your users' tastes and preferences, the system might base recommendations on item attributes alone. But the system needs to be able to learn from its users, collecting data about their tastes and preferences. Over time and with enough data, the system can use machine learning algorithms to perform useful analysis and deliver meaningful recommendations. Other users' inputs can also improve the results, enabling the system to be retrained periodically.

Step 1: Combines data from purchases, wish lists, shopping cart

Step 2: Uses collaborative filtering and product similarity for recommendations

Step 3: Exposes predictions to customers when browsing or buying. 


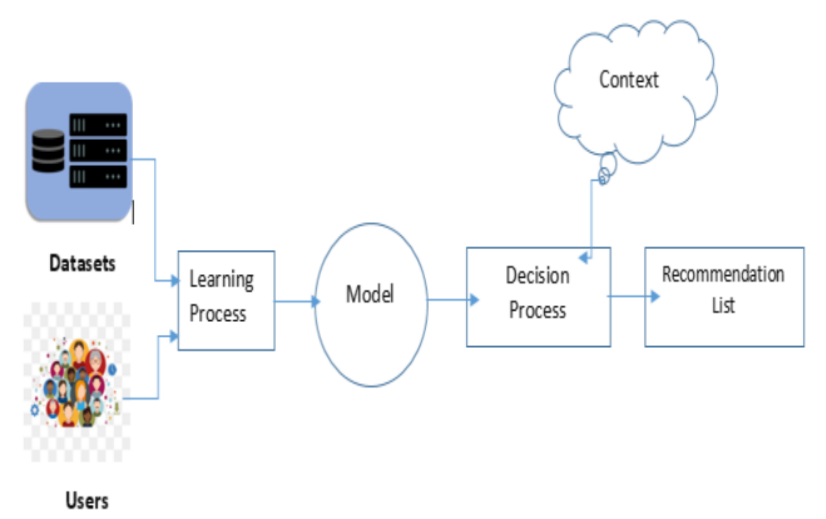

Figure 1. Recommendation Engine

\section{USER'S LOCATION DETECTION}

The following model uses the user's location for finding product demand at that location. Hence, the system needs to detect the user's location first. The location of user can be used for too many purposes like, displaying personalized content to the user according to their location, automatic language changing for different user of different countries and displaying targeted information to visitors from different locations. There are two ways to detect the user's location:-

- HTML5 Geolocation API

- IP Address Lookup

HTML5 Geolocation API - The Geolocation API is a new HTML5 feature that allows us to ask user for the permission to give their location. By implementing this feature we allow every visitor to share their location if they want. The Geolocation API helps to get the geographical position of the user.

Whenever a visitor will come to the website a Java script prompt is shown to the user asking them if they want to share their location or not. In this research we are going to use this feature with CodeIgniter which is a PHP framework. During the Signup we will call getCurrentPosition() method which create a prompt message to the user asking for the permission to give their location and if they will allow it will return the Latitude and Longitude of the user's position and then the position will be passed to the database using hidden inputs.

IP Address Lookup - It is another way of getting the user's location. The purposed model is going to uses this feature as a backup of the Geolocation API, since some browser may not support HTML5.

The system will use Public IP lookup services/API for this option. It has some drawback like, the country given by most IP lookup services is almost always accurate but the coordinates are not always accurate. Also, if the system is going to be making plenty of requests, some of these services require that we get an API Key, and that we will have to pay.

\section{REVERSE GEOCODING}

After getting the user's Latitude and Longitude we will convert it to a comprehensive address using the Google Maps Reverse Geocoding API. The system needs to convert the location into a human readable form which is possible using Reverse Geocoding.
When the system gets a readable location of the user then further applies data mining of the products which are not available to that location and then the system will be able to recommend specific products to the user.

\section{USER BEHAVIOR ANALYSIS}

The research also focuses on user behavior analysis. We can consider the different aspects as depicted in Fig.2. User behavior analysis is the most crucial part in e-commerce, because it let the seller understand the demand of customer. It helps to focus on the different improvement needed for a good sell.

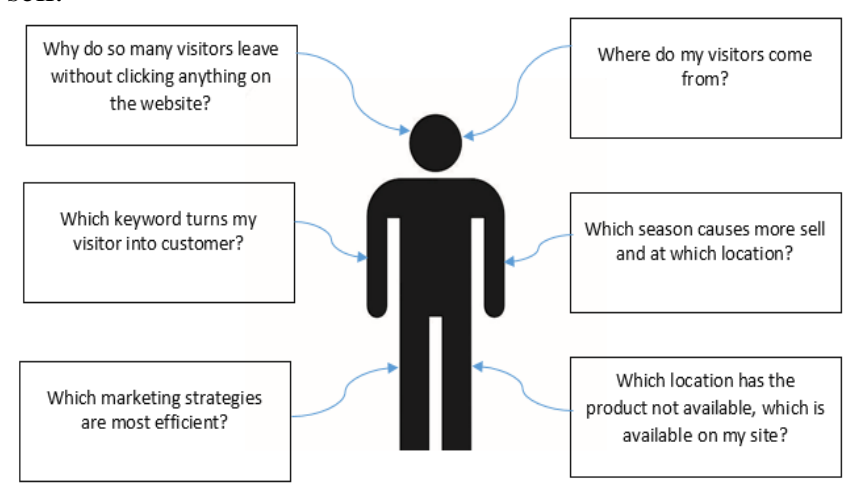

Figure 2. Strategy questions

\section{IMPORTANCE OF SMES IN INDIA}

SME is the abbreviation for Small and Medium Enterprises. These enterprises can be rightly called as the backbone of the GDP of India. The SME sector in India is growing at an exceptionally fast rate due to which it is proving to be beneficial to the Indian Economy.

- SSI is one of the significant segments of the Indian economy, contributing about 7 percent to the Indian GDP and providing employment to over 2 million people.

- The Indian SME segment's current production value is almost Rs. 816,000 crore.

- It contributes to around $40 \%$ of industrial production $\&$ exports.

- The SSI sector targets both domestic as well global markets.

- Globally, 99.7 per cent of all enterprises in the world are SMEs and the balance 0.3 percent are large-scale enterprises

- According to the Ministry of Small Scale Industries, the number of registered SSI units in India has increased from 11 million units in 2002-03 to 11.4 million units in 2003-04, up 3.6 percent.

\section{BENEFITS OF RECOMMENDATION SYSTEM}

Recommendation system helps an ecommerce developer to maintain and gain different benefits like:

- Deliver relevant content.

- Engage shoppers.

- Convert shoppers to customer.

- Increase average order value.

- Increase number of items per order.

- Reduce workload and overhead.

- Provide reports. 


\section{PROPOSED SYSTEM}

The proposed system will take benefit from the user location and user behavior and find out the efficient sell process and top selling items required by different persons residing at different locations. The proposed system asks user's to allow giving their location and does data mining on that location and find out what are the different product demands at that location. Based on that data the user is then recommended for those products.

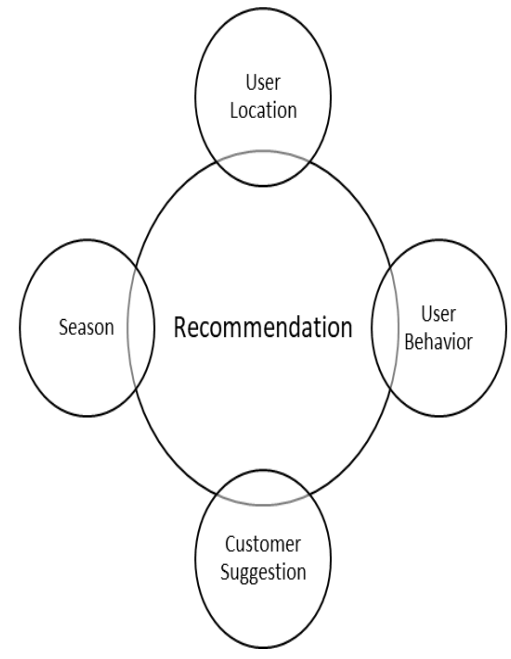

Figure 3. Recommendation aspects.

Recommendation can be based on four aspects:-User location, user behavior, season, and Customer suggestion. The next part of the model is to find the specific products which are not available at that location. So that the users of that location will get recommendation about that products. This model can help SMEs to know about the customer needs and they can target right customers for good sell.

The below table describes a seasonal sell on different locations. The research paper shows how in different seasons a seller or small medium enterprises can target different locations for sell improvement. From the following table we can see locations with important festival season are recommended with the products which have more chances to be sold out.

\begin{tabular}{|l|l|l|c|}
\hline Location & Season & \multicolumn{1}{|c|}{ Product } & $\begin{array}{c}\text { Recommendat } \\
\text { ion }\end{array}$ \\
\hline Kolkata & $\begin{array}{l}\text { Durga } \\
\text { Puja }\end{array}$ & $\begin{array}{l}\text { Printed topeto } \\
\text { silk saree }\end{array}$ & YES \\
\hline Chennai & Pongal & $\begin{array}{l}\text { Cream Art silk } \\
\text { saree }\end{array}$ & YES \\
\hline Assam & Bihu & Moga Silk saree & YES \\
\hline Patna & $\begin{array}{l}\text { Chhat } \\
\text { Puja }\end{array}$ & $\begin{array}{l}\text { Pooja } \\
\text { Embroidered } \\
\text { Bandhani Saree }\end{array}$ & YES \\
\hline Mathura & Holi & $\begin{array}{l}\text { Ethnic red/white } \\
\text { silk saree }\end{array}$ & YES \\
\hline
\end{tabular}

Figure 4. Examples of location and season sell

\section{USE CASE}

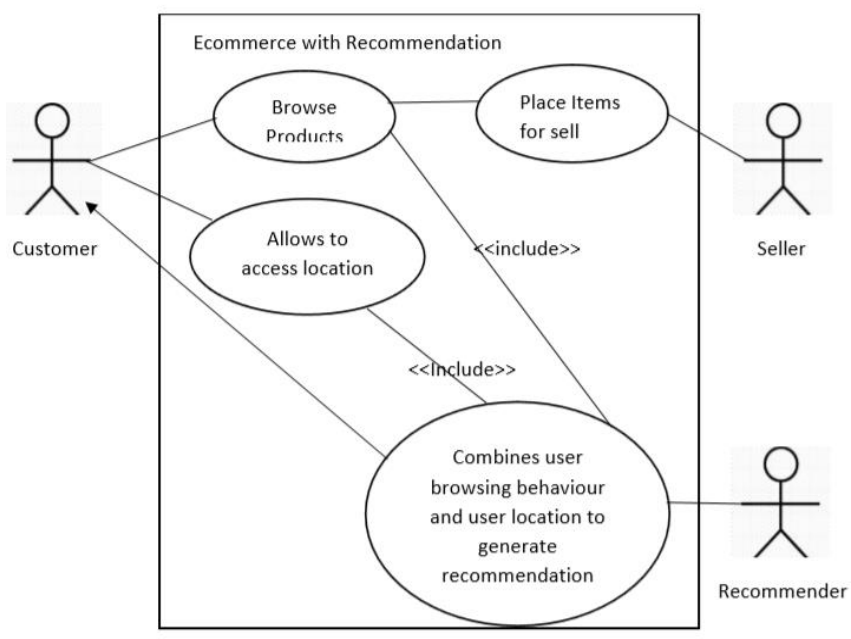

Figure 5. Use case diagram

\section{CONCLUSION}

Companies across many different areas of enterprise are beginning to implement recommendation systems in an attempt to enhance their customer's online purchasing experience, increase sales and retain customers. Business owners are recognizing potential in the fact that recommendation systems allow the collection of a huge amount of information relating to user's behavior and their transactions within an enterprise. This information can then be systematically stored within user profiles to be used for future interactions. As well as improving customer experience, the information gathered from a recommendation system can also be used as an ad targeting tool. By integrating a recommendation system with ad exchanges, a business may have the ability to target other website users with products they have liked on the company's site.

\section{ACKNOWLEDGMENT}

We are grateful to our institute for providing us support from all aspects.

\section{REFERENCES}

[1] Sumanta Chatterjee, Somsubhra Gupta. Information mining and e-marketing plan on real time data in cottage industries. In: International Journal of Engineering and Applied Sciences (IJEAS) ISSN: 2394-3661, Volume-4, Issue-10, October 2017

[2] Broser, C., Fritsch, C., Gmelch, O., Pernul, G., Schillinger, R. Wiesbeck, S., 2009. Analysing requirements for virtual business alliances the case of SPIKE. Digital Business. Lecture Notes for Computer Sciences, Social Informatics and Telecommunications Engineering, vol. 21. Springer, pp. 35-44.

[3] Diop, C., Exposito, E., Drira, K., Chassot, C., 2012. Semantic-driven autonomic service bus, in enterprise interoperability. In: Proceedings of the 2012 Conference on Interoperability for Enterprise Systems and Applications, I-ESA'12. John Wiley and Sons, Hoboken, NJ

[4] Redwood City, CA. Pedrinaci, C., Domingue, J., Brelage, C., van Lessen, T., Karastoyanova, D., Leymann, F., 2008. Semantic business process management: scaling up the management of business processes. In: Santa Clara, C.A. (Ed.), Proceedings of IEEE International Conference on Semantic Computing. IEEE Computer Society Press, Los Alamitos, CA, pp. 546-553.

[5] Zhao Huang, Morad Benyoucef, "From e-commerce to social commerce: A close look at design features", Electronic Commerce Research and Applications, Elsevier, Volume 12, Issue 4, Pages 246-259, July- August, 2013. 
Product Recommendation Making Based on User Behavior and User location and Potential of E-commerce for SMEs in a Globalizing Business Environment

[6] L. Byron. "Study on Electronic Commerce and Security", International Journal of Advanced Research in Computer and advanced engineering. Volume -1, Issue -5 . Pages (5-7), July 2012

[7] https://searchsecurity.techtarget.com/definition/user-behavior-

[8] http://users.metu.edu.tr/home303/e133376/wwwhome/project/Behavi or\%20Analysis\%20Model.html

[9] (Security Algorithms for User Behavior Analysis in Cloud Environment: A Survey) Thiruchendhil Arasu1, Dr. E. George Dharma Prakash Raj2, B. Prashant 3. December 2017). Journal [IJRASET]. Volume 5 Issue XII, Available https://www.ijraset.com/fileserve.php?FID=11908

[10] Vladimir Zwass. (2004, February). International Journal of Electronic Commerce https://link.springer.com/chapter/10.1057/978-1-137-56473-3_3

[11] Fensel, D., Fischer, F., Kopecky, J., Krummenacher, R., Lambert, D., Vitvar, T., 2010. WSMO-Lite: light-weight semantic descriptions for services on the web. W3C Member Submission, August 23

[12] Niranjanamurthy $M$ and Dharmendar chchar. "The Study of e-commerce security Issues and Solutions "International Journal of Advanced Research in Computer and advanced engineering. Volume -2, Issue -7 . Pages (5-7), July 2013.

Mr. Sumanta Chatterjee is presently working as an Assistant Professor of JIS College of Engineering, Kalyani, Nadia, West Bengal. He has worked 2 years in the Industry and 5 years in the Academic Sector. He completed his M.Tech degree in Computer Science and Engineering and B.Tech degree in Information Technology from West Bengal University of Technology. He is recently working on the emerging research field "E-Commerce ".He has made significant contribution on the research field "E-Commerce". He has published more than 16 research papers, having 1 Funded Projects as Principal Investigator $\mathrm{He}$ is a member of International Association of Computer Science and Information Technology (IACSIT) and also a member of International Association for Engineers (IAENG).

Nilesh Kumar is presently a student of JIS College of Engineering. He is in final year of B.Tech in Computer Science and Engineering. He is currently researching on different aspects for product recommendation using Artificial Intelligence and Data mining.

Debarishi Saha is presently a student of JIS College of Engineering. He is in final year of B.Tech in Computer Science and Engineering. He is currently researching on different aspects for product recommendation using Artificial Intelligence and Data mining.

Dipu Keshri is presently a student of JIS College of Engineering. He is in final year of B.Tech in Computer Science and Engineering. He is currently researching on different aspects for product recommendation using Artificial Intelligence and Data mining.. 